\title{
Formulation, Development and Evaluation of Colon-specific Ketorolac Tromethamine Compression Coated Tablets
}

\author{
Sateesh Kumar Vemula ${ }^{1 *}$, Selamu Kebamo ${ }^{1}$, Biniam Paulos ${ }^{1}$ and Vijaya Kumar Bontha ${ }^{2}$ \\ ${ }^{1}$ Department of Pharmacy, College of Medical and Health Sciences, Wollega University, Post Box No: 395, \\ Nekemte, Ethiopia \\ ${ }^{2}$ Department of Pharmaceutics, Jangaon Institute of Pharmaceutical Sciences, Yeshwanthapur, Jangaon, \\ Warangal-506167, Telangana, India

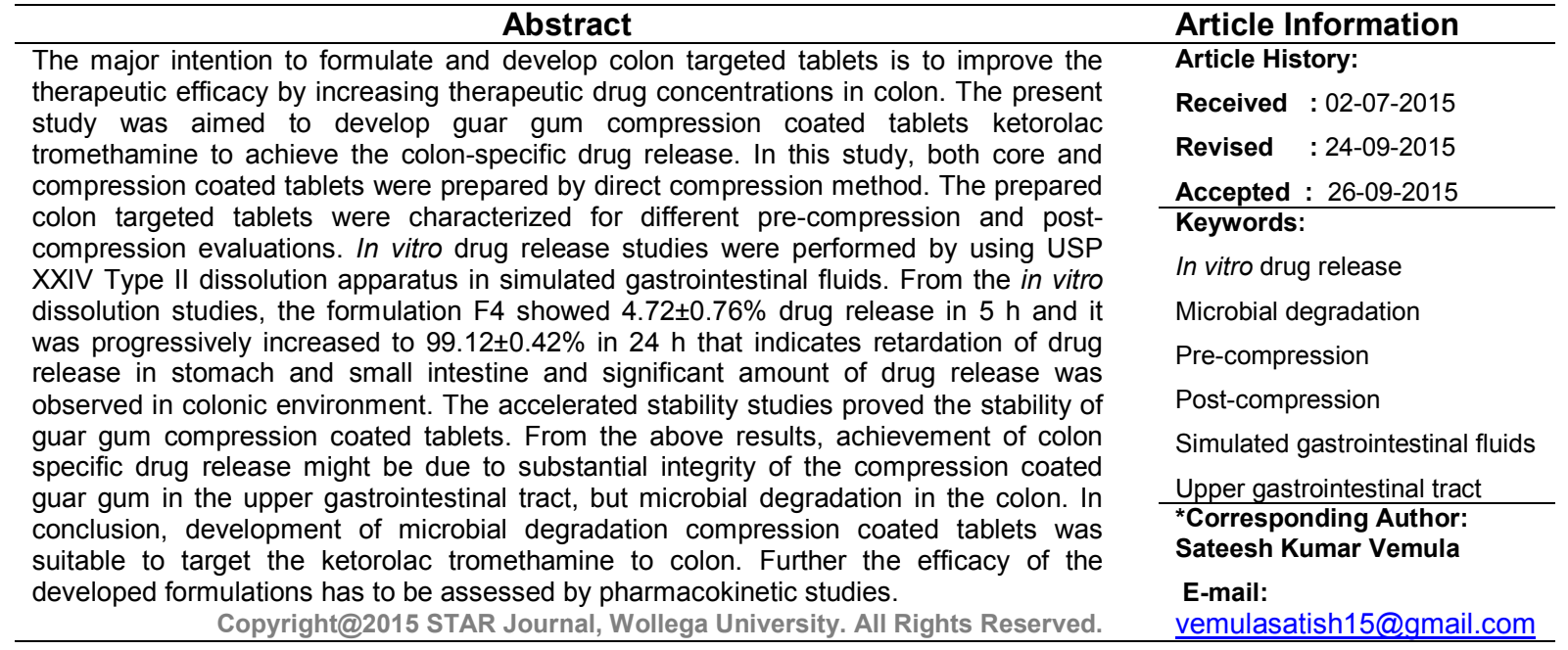

\section{INTRODUCTION}

Progressive development of new formulations of previously marketed drugs using current formulation technologies is the latest trend in pharmaceutical industries to overcome high expenses and longer duration requirement in the new drug development (Vemula and Veerareddy, 2013). Formulation of colon-targeted/colonspecific tablets is one of the examples for above that enhance the therapeutic efficacy by rising colonic drug concentrations (Vincent and Suman, 2002). Development of colon-specific medication is useful to treat local disorders of colon as well as to improve the delivery of proteins and peptides (Vemula et al., 2014a). Colon targeting can achieve by employing the principles like prodrug approach, pH-sensitive drug delivery, timedependent delivery systems, and microbial degradation methods (Vemula and Veerareddy, 2009). Among the above, microbial degradation system is the most widespread and successful strategy to design the colon targeted formulations, which is fit to retard the drug release in initial lag period (stomach and small intestine) and gives complete drug release in sustained manner within the colon (Sinha and Kumaria, 2002).
Ketorolac Tromethamine (KTM), classified as non steroidal anti-inflammatory drug (NSAID) used to treat colonic inflammation and pain, but leads to gastric ulceration due to frequent intake KTM (Brahmankar et al., 1996). As a result the, development of colonic delivery of KTM is to overcome its adverse symptoms and to achieve high local drug concentration in the colon. Hence it is decided to develop a microbial degraded guar gum compression coated tablets of KTM for colon specific delivery in the present study, not only to retard the release of the drug in the upper gastro intestinal tract (GIT) and also to give slow and complete drug release in colon. Some of the recent research examples reported in literature on KTM colon-specific tablets are Formulation and pharmacokinetics of colon-specific doublecompression coated pulsatile mini-tablets of ketorolac tromethamine (Vemula, 2015a), Colon-specific doublecompression coated pulsatile tablets of ketorolac tromethamine (Vemula and Katkum 2015a), timedependent ketorolac tromethamine-sodium alginate compression coated tablets (Vemula et al., 2014), timedependent ketorolac tromethamine compression coated tablets using HPMC (Vemula and Veerareddy, 2013), 
Sateesh Kumar Vemula et al.,

eudragit coated ketorolac tromethamine-hydroxypropyl methylcellulose $\mathrm{pH}$ and time-dependent matrix tablets (Vemula and Veerareddy, 2012) etc.

Guar gum (GG), a natural polymer classified as galactomannan polysaccharide form Cyamopsis tetragonolobus (Sinha and Kumaria, 2001). GG is widely used polymer to develop the colon-specific drug delivery systems and some of the research examples for GG colon targeted formulations are ketorolac tromethamine (Vemula and Katkum 2015b), flurbiprofen (Vemula and Bontha, 2013), tamoxifen (Randhawa et al., 2012), 5amino-salicylic acid (Ji et al., 2008; Krishnaiah et al., 1998), trimetazidine dihydrochloride (Krishnaiah et al., 2002) and mebendazole (Krishnaiah et al., 2001). The objective of the study was to formulate KTM-GG colon targeted compression coated tablets.

\section{MATERIALS AND METHODS}

Materials

Ketorolac Tromethamine was gift sample from Bright Labs, Hyderabad, India. Guar gum and HPMC K4M were gift samples from Matrix laboratories, Hyderabad, India. All other chemicals used were of analytical grade.

Preparation of Core and Compression Coated Tablets

Direct compression method was employed to prepare the KTM core and compression coated tablets using Avicel PH 102 as diluent (Vemula, 2015b). Accurately weighed quantity of KTM and excipients other than glidant and lubricant passed through 60 mesh sieve and mixed in a poly sack for 5-10 min. Then the obtained blend was lubricated with talc and magnesium stearate for $5 \mathrm{~min}$ and compressed into tablets with $6 \mathrm{~mm}$ round flat punches using 8 station rotary tabletting machine. The amount of KTM present in each tablet was $20 \mathrm{mg}$ and the final weight was acclimated to $80 \mathrm{mg}$ (Table 1). Then the core tablets were compression coated with different compositions of coats given in Table 2 using the procedure given in Veerareddy \& Vemula, 2012 with 8 $\mathrm{mm}$ round, flat and plain punches.

Table 1: Composition and characterization of KTM core tablets

\begin{tabular}{lc}
\hline Ingredients & $\begin{array}{c}\text { Quantity } \\
\text { (mg) }\end{array}$ \\
\hline Ketorolac tromethamine & 20 \\
Avicel PH 102 & 53 \\
Crosspovidone & 4 \\
Talc & 1 \\
Magnesium stearate & 2 \\
Core weight & 80 \\
\hline
\end{tabular}

Table 2: Composition of KTM colon specific compression coated tablets

\begin{tabular}{cccc}
\hline $\begin{array}{c}\text { Formulation } \\
\text { Code }^{*}\end{array}$ & $\begin{array}{c}\text { KTM Core } \\
\text { Tablet (mg) }\end{array}$ & $\begin{array}{c}\text { Guar } \\
\text { Gum (mg) }\end{array}$ & $\begin{array}{c}\text { Total tablet } \\
\text { weight }(\mathbf{m g})\end{array}$ \\
\hline F1 & 80 & 25 & 280 \\
F2 & 80 & 50 & 280 \\
F3 & 80 & 75 & 280 \\
F4 & 80 & 100 & 280 \\
F5 & 80 & 120 & 280
\end{tabular}

* Each compression coat formulation contains 1\% Magnesium stearate, 2\% Talc and Avicel PH 102 to make up the compression coat weight to $200 \mathrm{mg}$.
Sci. Technol. Arts Res. J., July-Sep 2015, 4(3): 150-154

\section{Estimation of Tablet Physical Parameters}

The prepared tablets were assessed for weight variation, hardness, friability and for drug content. To compute the weight variation, 20 tablets of each formulation were weighed using an electronic weighing balance (Shimadzu, Japan) and determined the average weight and deviation. The hardness of six tablets was measured using Monsanto tablet hardness tester. Friability was calculated on ten tablets in a Roche friabilator (Electrolab, India). Drug content uniformity was estimated by randomly picked ten tablets and taken the drug powder equivalent to $100 \mathrm{mg}$ by crushing the selected tablets to prepare the drug solution and finally analyzed for at $322 \mathrm{~nm}$ (Vemula, 2015c).

\section{In vitro dissolution study}

In vitro dissolution study was conducted using USP XXIV Type I dissolution apparatus (Electro lab, TDT-08L) at $50 \mathrm{rpm}$ rotation speed and $37 \pm 0.5^{\circ} \mathrm{C}$ temperature. To mimic the gastrointestinal environment, dissolution test was performed in different dissolution media. Initially, the drug release was carried out for $2 \mathrm{~h}$ in simulated gastric fluid (SGF, $\mathrm{pH} 1.2$ ), then in enzyme-free simulated intestinal fluid (SIF, $\mathrm{pH} \mathrm{6.8)} \mathrm{for} 3 \mathrm{~h}$, the average small intestinal transit time and finally in simulated colonic fluid (SCF) i.e., pH 6.8 phosphate buffer containing $4 \% \mathrm{w} / \mathrm{v}$ of rat caecal contents up to $24 \mathrm{~h}$ to simulate colonic environment. At pre-determined time intervals, $5 \mathrm{ml}$ samples were withdrawn, filtered and analyzed at $322 \mathrm{~nm}$ using UV-Visible spectrophotometer. Then using the above dissolution data, calculated the mean dissolution time (MDT), T10\% and T80\% (time in hours to take 10\% and $80 \%$ drug release) to explain the colon-specific drug release from prepared KTM-GG compression-coated tablets (Talukder and Fassihi, 2008; Vemula and Veerareddy, 2013).

\section{Stability studies}

Stability studies were designed to assess the stability of KTM in compression coated tablets using $\mathrm{ICH}$ guidelines. Three replicates of formulation F4 tablets were sealed in aluminum coated inside with polyethylene pack and stored at $40 \pm 2{ }^{\circ} \mathrm{C}$ and $75 \pm 5 \% \mathrm{RH}$ in the humidity chamber for six months (Chaudhary et al., 2011). Collected samples after six months of storage were evaluated for the drug content and in vitro dissolution rate (Mathews, 1999). Then similarity factor was calculated between dissolution rates of optimized tablets before and after storage. At this point, the data was statistically analyzed using paired $t$-test to test the significance of difference at level of significance 0.05 (Vemula and Katkum, 2014).

\section{RESULTS AND DISCUSSION}

\section{Estimation of Tablet Physical Parameters}

Various physical parameters of prepared tablets were determined. In these, the weight variation of the tablets was found in the range of $279.25 \pm 2.96-281.34 \pm 3.18 \mathrm{mg}$ and all the formulation tablets were fell within the pharmacopoeial limit i.e., average weight $\pm 5 \%$. The thickness $(2.97 \pm 0.04 \mathrm{~mm})$ and diameter $(8.03 \pm 0.02 \mathrm{~mm})$ of the tablets were found to be uniform in all formulations. The hardness of the tablets was found as $5.93 \pm 0.28$. $6.04 \pm 0.13 \mathrm{~kg} / \mathrm{cm}^{2}$. The percentage friability for all formulations was underneath $1 \%$ i.e. $0.24 \%-0.36 \%$, demonstrating that the friability is inside as far as possible. The tablets were found to contain $100.14 \pm 1.56$ $98.25 \pm 1.38 \%$ of the labeled amount indicating uniformity 


\section{Sateesh Kumar Vemula et al.,}

of drug content. All the tablet formulations were complied with pharmacopoeial standards, so all the tablets were with worthy physical attributes. In weight variation test, the pharmacopoeial limit for tablets is not more than $5 \%$ of the average weight. The average percentage deviation of all tablet formulations was discovered to be inside as far as possible and henceforth all formulations passed the uniformity of weight as per the official requirements of Indian Pharmacopoeia, (1996). From the physical characterization, all the tablet formulations were uniform in hardness, friability and drug content uniformity.

\section{In vitro Dissolution Study}

Figure 1 demonstrated the release profiles of KTM from the compression coated tablets containing different
Sci. Technol. Arts Res. J., July-Sep 2015, 4(3): 150-154

levels of GG (F1-F5) and it was found to vary from $4.61 \pm 0.12$ to $98.72 \pm 0.36 \%$ after $5 \mathrm{~h}$ of testing in simulated gastric and intestinal fluids and the percent drug release was progressively improved after $5 \mathrm{~h}$ and it was found to be $78.56 \pm 0.21$ to $99.12 \pm 0.42 \%$ in $24 \mathrm{~h}$ testing in simulated colonic fluid. From the consequences of in vitro drug release studies thinks about, the cumulative mean percent of KTM discharged from compression coated tablets containing shifting measures of GG $(25 \mathrm{mg}, 50 \mathrm{mg}, 75$ $\mathrm{mg}, 100 \mathrm{mg} \mathrm{\&} 125 \mathrm{mg}$ ), joining of $100 \mathrm{mg}$ of polymer in the aggregate tablet weight (F4) was discovered to be satisfactory to define a tablet with great respectability and acceptable in vitro drug release i.e., $4.72 \pm 0.76 \%$ drug release in $5 \mathrm{~h}$ and it was continuously expanded to $99.92 \pm 0.42 \%$ in $24 \mathrm{~h}$.

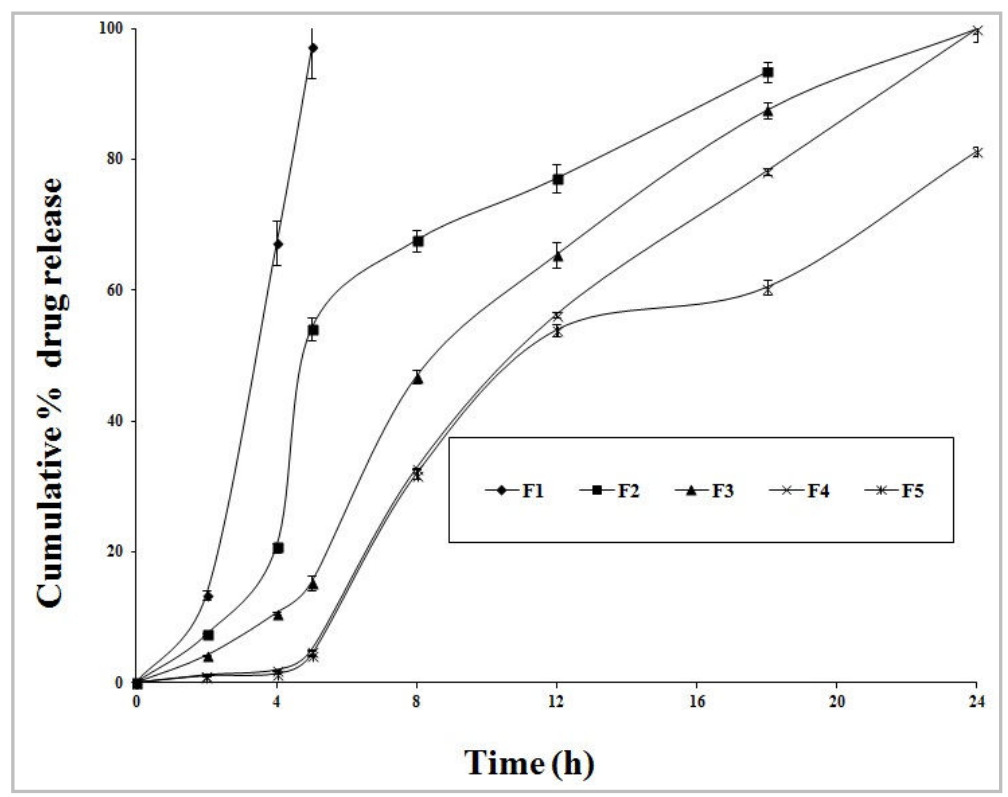

Figure 1: Release profile of KTM from GG compression coated tablets $(n=3)$

Optimization of compression coat weight was done to gain the significant protection in upper GIT and suitable dissolution profiles in colon by formulating the compression coated tablets with distinctive GG coat weights. By comparing the drug release profiles of above formulations, $200 \mathrm{mg}$ coat weight was found as the suitable compression coat weight. Then drug release studies were carried out for F1-F5 formulations containing distinctive GG weight, and the results demonstrated that $100 \mathrm{mg}$ of GG in $200 \mathrm{mg}$ of compression coat was proved as best among others. Similar type of results was observed in flurbiprofen guar gum compression coated tablets conducted by Vemula and Bontha, (2013) that signifies the potential utility of GG as colon-specific polymer. But in comparison to other reported study by Krishnaiah et al. (1998), $125 \mathrm{mg}$ of GG in the coat weight of $175 \mathrm{mg}$ for indomethacine was showed similar type of results.

In the present study, dissolution studies of F1-F5 formulations demonstrate the impact of GG amount on KTM release from the prepared compression coated tablets and this study showed negligible drug release $(5 \%)$ in the upper GIT environment and dynamic drug release was observed in the colon environment with 100 $\mathrm{mg}$ of GG (F4 formulation). From these results, the formulation F4 considered as the best formulation that demonstrated $4.72 \pm 0.76 \%$ drug release in the initial lag period $(5 \mathrm{~h}$ ) followed by $99.92 \pm 0.42 \%$ drug release for 24 $\mathrm{h}$ in a slow manner. Formulations with higher than $100 \mathrm{mg}$ of $G G$ gave minimum drug release in the initial lag time, but failed to complete the drug release in $24 \mathrm{~h}$. By giving importance to mechanical strength of tablets, $5 \%$ HPMC $\mathrm{K} 4 \mathrm{M}$ was incorporated in compression coat to magnify the mechanical strength because GG alone failed to give sufficient mechanical strength due to its low compressibility. Comparable kind of perceptions was seen in piroxicam guar gum compression coated tablets formulated by Veerareddy and Manthri, (2010).

The MDT values were found to be 2.41-13.92 $\mathrm{h}$. The $\mathrm{T} 10 \%$ and $\mathrm{T} 80 \%$ values of optimized formulation (F4) was found to be $5.8 \mathrm{~h}$ and $17.9 \mathrm{~h}$ respectively (Figure 2). From the dissolution data, the computed mean dissolution time was increased as increasing the concentration of GG demonstrate the sustained release capacity of polymer and the time in hours to take $10 \%$ and $80 \%$ drug release ( $\mathrm{T} 10 \%$ and $\mathrm{T} 80 \%$ ) were able to illustrate the capability of GG as colon specific polymer. The above calculated parameters demonstrated that the $\mathrm{F} 4$ formulation compression coated tablets gave not only $5 \mathrm{~h}$ lag time to reach colon but also gave the complete drug release in colon in slow manner in contrast to other formulations. 


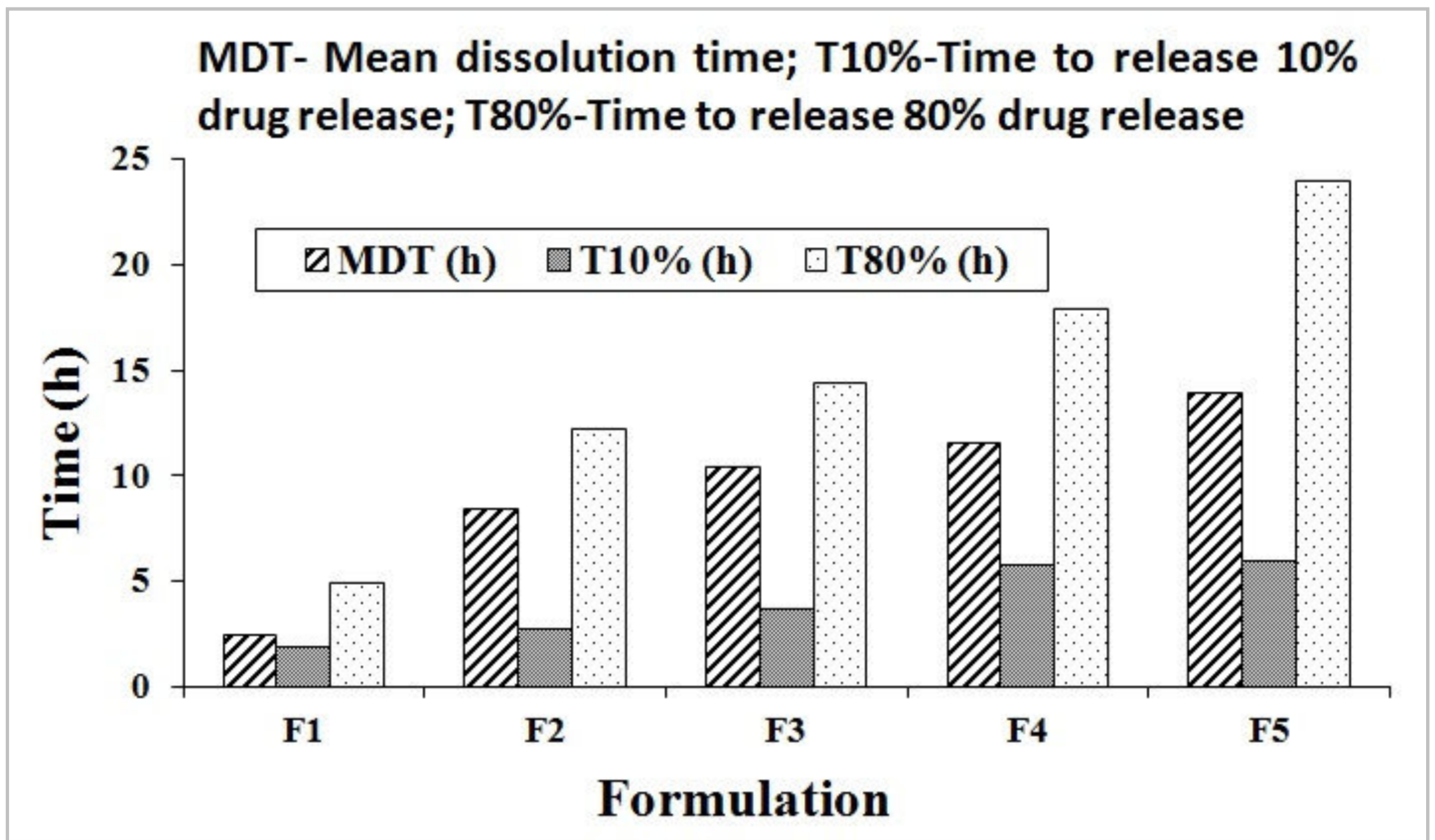

Figure 2: Drug release parameters of KTM-GG compression coated tablets

\section{Stability Studies}

Stability studies were performed at $40 \pm 2^{\circ} \mathrm{C}$ and $75 \pm 5 \%$ $\mathrm{RH}$ for six months for selected F4 tablets. After storage of six months, the tablets were evaluated to assay and dissolution studies (Figure 3). The stability studies data of F4 formulation revealed that there was no significant change in drug content and dissolution rate of tablets before and after storage. The similarity index value was found as 83.42 , which is more than 50 indicates similarity between the dissolution profile before and after storage. From the statistical analysis there was no significant difference between before and after storage $(p<0.05)$.
From the above results, F4 formulation was considered as the best formulation that gave less than $5 \%$ drug release in $5 \mathrm{~h}$ and it was progressively increased to $100 \%$ in $24 \mathrm{~h}$, which demonstrates just a little measure of medication was discharged in stomach and small intestine, and a measurable quantity of drug was released in colonic environment with the help of microbial degradation of GG. From all these perceptions it was inferred that the colon targeted GG compression coated tablets were indicated immaterial KTM release in stomach and small intestine, yet released promisingly in colon.

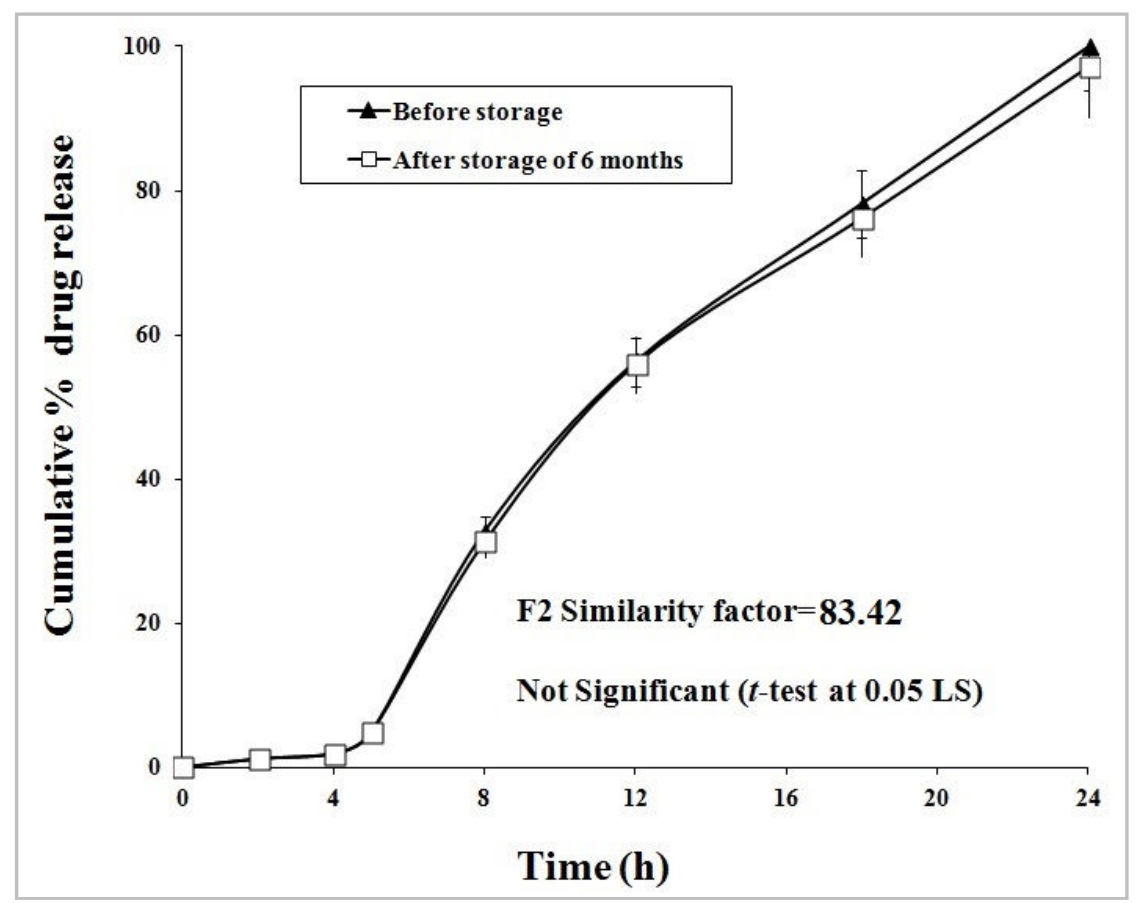

Figure 3: Effect of stability studies on the release profile of KTM from GG colon targeted compression coated tablet F4 $(n=3)$ 
Sateesh Kumar Vemula et al.,

\section{CONCLUSION}

In the present study, considerable effort was put to formulate and develop the successful colon-specific system of KTM using guar gum compression coated tablets to generate the colon specific drug release without loss in the stomach and small intestine. From the in vitro drug release studies, F4 formulation showed significant amount of drug release in the colon with minimum release in lag period of $5 \mathrm{~h}$ with proved stability of drug in GG compression coat. The stability studies data of F4 formulation revealed that there was no significant change in drug content and dissolution rate of tablets before and after storage. The similarity index value was found as 83.42 , which is more than 50 indicates similarity between the dissolution profile before and after storage. In conclusion, development of GG compression coated tablets using microbial dependent strategy is an appropriate approach for colon targeting of KTM.

\section{Conflict of Interest}

Conflict of interest none declared.

\section{Acknowledgements}

The authors acknowledge Bright Labs and Matrix laboratories, Hyderabad, India for providing Ketorolac Tromethamine, Guar gum and HPMC K4M as gift. The authors also thank Jangaon Institute of Pharmaceutical Sciences, Jangaon, India for providing the facilities.

\section{REFERENCES}

Brahmankar, D.M., Karwa, R.M., Jaiswal, S.B. (1996). Cellulose matrix for controlled release of keterolac tromethamine. Indian Drugs 33(3): 120-123.

Chaudhary, A., Tiwari, N., Jain, V., Singh, R. (2011). Microporous bilayer osmotic tablet for colon-specific delivery. European Journal of Pharmaceutics and Biopharmaceutics 78: 134-140.

Ji, C.M., Xu, H.N., Wu, W. (2008). Guar Gum as Potential Film Coating Material for Colon-specific Delivery of Fluorouracil. Journal of Biomaterials Applications 1-20.

Krishnaiah, Y.S.R., Satyanarayana, S., Ramaprasad, Y.V., Narasimharao, S. (1998). Evaluation of guar gum as a compression coat for drug targeting to colon. International Journal of Pharmaceutics 171: 137-146.

Krishnaiah, Y.S.R., Veerraju, P., Kumar, D.A. (2001). Development of colon targeted drug delivery systems for mebendazole. Journal of Controlled Release 77: 87-95.

Krishnaiah, Y.S.R., Karthikeyan, R.S., Sankar, G.V. (2002). Three-layer guar gum matrix tablet formulations for oral controlled delivery of highly soluble trimetazidine dihydrochloride. Journal of Controlled Release 81: 45-56.

Mathews, B.R. (1999). Regulatory aspects of stability testing in Europe. Drug Development and Industrial Pharmacy 25: 831-56.

Randhawa, R., Bassi, P., Kaur, G. (2012). In vitro, in vivo evaluation of inter polymer complexes between carboxymethyl fenugreek gum and chitosan or carboxymethyl guar gum and chitosan for colon delivery of tamoxifen. Asian Pacific Journal of Tropical Disease 202-207.

Sinha, V.R., Kumaria, R. (2001). Polysaccharides in colonspecific drug delivery. International Journal of Pharmaceutics 224: 19-38.

Sinha, V.R., Kumaria, R. (2002). Binders for colon specific drug delivery: an in vitro evaluation. International Journal of Pharmaceutics 249: 23-31.
Sci. Technol. Arts Res. J., July-Sep 2015, 4(3): 150-154

Talukder, R.M., Fassihi, R. (2008). Development and in-vitro evaluation of a colon-specific controlled release drug delivery system. Journal of Pharmacy and Pharmacology 60: 1297-1303.

Veerareddy, P.R., Manthri, R.P. (2010). Formulation and evaluation of compression coated piroxicam tablets for colon specific drug delivery. Acta Pharma Scientica 52: 281-294.

Veerareddy, P.R., Vemula, S.K. (2012). Formulation, evaluation and pharmacokinetics of colon targeted pulsatile system of flurbiprofen. Journal of Drug Targeting 20(8): 703-714.

Vemula, S.K., Veerareddy, P.R. (2009). Different approaches to design and evaluation of colon specific drug delivery systems. International Journal of Pharmacy and Technology 1(1): 1-35.

Vemula, S.K., Veerareddy, P.R. (2011). Formulation and evaluation of Ketorolac tromethamine tablets for time and $\mathrm{pH}$ dependent colon specific delivery. Journal of Current Pharmaceutical Research 8(1): 31-39.

Vemula, S.K., Veerareddy, P.R. (2013). Formulation, evaluation and pharmacokinetics of ketorolac tromethamine time-dependent colon targeted drug delivery system. Expert Opinion on Drug Delivery 10:33-45.

Vemula, S.K., Bontha, V.K. (2013). Colon targeted gaur gm compression coated tablets of flurbiprofen: formulation, development and pharmacokinetics. BioMed Research International 2013: 1-8.

Vemula, S.K., Katkum, R. (2014). Development and physical characterization of meclizine hydrochloride solid dispersions by using polyethylene glycol 8000 . Science, Technology and Arts Research Journal 3(1): 48-52.

Vemula, S.K., Veerareddy, P.R., Devadasu, V.R. (2014). Pharmacokinetics of ketorolac tromethamine compression -coated tablets for colon delivery. Drug Delivery and Translational Research 4: 310-319.

Vemula, S.K., Veerareddy, P.R., Devadasu, V.R. (2015). Pharmacokinetics of colon-specific $\mathrm{pH}$ and timedependent flurbiprofen tablets. European Journal of Drug Metabolism and Pharmacokinetics 40 (3): 301-311.

Vemula, S.K. (2015a). Formulation and pharmacokinetics of colon-specific double-compression coated pulsatile minitablets: Chronopharmaceutical delivery of ketorolac tromethamine. International Journal of Pharmaceutics 491: 35-41.

Vemula, S.K. (2015b). A novel approach to flurbiprofen pulsatile colonic release: Formulation and pharmacokinetics of double-compression coated minitablets. AAPS PharmSciTech 16:1465-1473.

Vemula, S.K. (2015c). Colon specific drug delivery: Effect of eudragit enteric coating on hydroxypropyl methylcellulose matrix tablets of flurbiprofen. Journal of Young Pharmacists 7 (4): 373-383.

Vemula, S.K., Katkum, R. (2015a). Colon-specific doublecompression coated pulsatile tablets of ketorolac tromethamine: Formulation development and pharmacokinetics. Journal of Drug Delivery Science and Technology 29: 78-83.

Vemula, S.K., Katkum, R. (2015b). Formulation, Development and pharmacokinetics of ketorolac tromethamine colon targeted guar gum compression coated tablets. Analytical Chemistry Letters 5(3):149-161.

Vincent, H.L., Suman, K.M. (2002). Drug delivery-oral colonspecific. In: Swarbick, J., Boylan, C.J., ed. Encyclopedia of Pharmaceutical Technology. New York: Marcel Dekker, pp 871-885. 